\title{
Ergonomic Evaluation of the Perceived Mental Workload among Tunisian University Hospital Caregivers
}

\author{
Lamia Bouzgarrou ${ }^{1,2}$, Irtyah Merchaoui ${ }^{1,3}$, Amira Omrane $^{1,2^{*}}$, Nada Ameur ${ }^{2}$, Jacques Malchaire ${ }^{4}$, \\ Neila Chaari ${ }^{1,3}$
}

${ }^{1}$ Department of Occupational Medicine and Ergonomics, Faculty of Medicine, University of Monastir, Monastir, Tunisia

${ }^{2}$ Department of Occupational Medicine, University Hospital of Taher Sfar, Mahdia, Tunisia

${ }^{3}$ Department of Occupational Medicine, University Hospital of Fattouma Bourguiba, Monastir, Tunisia

${ }^{4}$ Hygiene and Work Physiology Unit, Catholic University of Louvain, Brussels, Belgium

Email: *om raneamira@yahoo.fr

How to cite this paper: Bouzgarrou, L., Merchaoui, I., Omrane, A., Ameur, N., Malchaire, J. and Chaari, N. (2017) Ergonomic Evaluation of the Perceived Mental Workload among Tunisian University Hospital Caregivers. Open Journal of Nursing, 7, 1144-1156.

https://doi.org/10.4236/ojn.2017.710083

Received: May 10, 2017

Accepted: October 15, 2017

Published: October 18, 2017

Copyright $\odot 2017$ by authors and Scientific Research Publishing Inc. This work is licensed under the Creative Commons Attribution International License (CC BY 4.0).

http://creativecommons.org/licenses/by/4.0/

\section{Open Access}

\begin{abstract}
Objectives: To evaluate the perceived mental workload and to identify its individual and professional determinants among Tunisian caregivers in university hospitals. Methods: A cross-sectional study was carried out in two university hospitals of the center of Tunisia, which employ 1179 paramedics providing care activities. The survey was conducted within a representative sample, of 301 caregivers assigned to 28 medical and surgical services, randomly drawn, after being paired according to age, gender and work schedule. It included structured inquiry (socio-professional characteristics, occupational perceived workload) and validated questionnaires (Job Content Questionnaire of Karasek, SF12, WAI). Results: Mental workload was perceived as "moderate" by 145 caregivers $(48.49 \%)$ and as "heavy" by 119 caregivers $(40.61 \%$ of them). Among the sample, 209 paramedics endured at least once the fixed night work schedules along their respective careers, with an average of $5.63 \pm$ 7.54 years. According to the WAI index, $39.59 \%$ of subjects considered their capacity of work as low. Moreover, job strain was noted in $19.79 \%$. Indeed, work latitude was unsatisfactory among $41 \%$ of caregiver, $60.1 \%$ of them mentioned the absence of colleagues' support. A feeling of job insecurity was reported by $73.72 \%$ of subjects. Multi-varied analytic study concluded that heavier perceived mental work load was correlated to individual determinants particularly age $>45$ years $\left(\mathrm{p}<10^{-3}\right)$, overweight or obesity $(\mathrm{p}=0.02)$, more than three depending children $\left(\mathrm{p}<10^{-3}\right)$, lower degree obtained $\left(\mathrm{p}<10^{-3}\right)$, working grade as nurse assistant $(\mathrm{P}=0.001)$, lower quality of physical life $(0.010)$ and expressed willingness to retire early $(p=0.003)$. Conclusion: The
\end{abstract}


heavy perception of mental workload associated to care activities, is one of the reasons of premature departure among nurses from professional activity. Preventive actions on professional determinants of perceived workload can reduce this phenomenon.

\section{Keywords}

Mental Workload, Nurses, Ergonomic, Prevention

\section{Introduction}

Even if not clear, a universally accepted definition of workload exists. "Mental workload" refers to both the requirements of the task and the individual resources available when executing an operation [1] [2] [3].

Workload is multidimensional and multifaceted construct. It is the result of many different demands and can be influenced by numerous factors in the environment of work [3] [4]. An inadequacy between these requirements and skills can be observed. This inadequacy can be particularly prominent through an event demanding high constraints with limited mobilizable resources, leading to a situation of a "mental overload at work". This situation can affect both the health of the worker and the work performance [1] [4] [5].

Researches show that the sector of care is characterized by a high mental load, especially due to rapid and important development of knowledge, perpetual renewal of medical and paramedical techniques, and the specificity of the object of work (the diseased man) involving a direct confrontation with a suffering human [2]. The perceived mental workload associated to nurse activity varies according to various determinants. These determinants are related to both individuals' characteristics, nursing activity and work environment characteristics [1] [2]. Furthermore, concerning nurses, heavy mental workload negatively affects patient's safety, job satisfaction and nurse's health. Thus it contributes to high turnover and the nursing shortage [6].

This study aims to evaluate the perceived mental work load and to identify its individual and professional determinants among Tunisian caregivers in university hospitals.

\section{Patients and Methods}

A cross-sectional study was conducted during 15 months in two university hospitals in central Tunisia which employ 1.179 paramedics practicing nursing care.

Caregiver practicing exclusively administrative tasks or managing teams and equipment were excluded of the survey. Moreover, in each hospital, the department of occupational medicine ensures the periodic follow-up of medical staff and paramedics. Thus, based on these medical records, we identified and excluded subjects suffering from psychological or neuropsychiatric disorders. In 
total, 882 paramedics performing nursing activities were concerned by the survey.

A representative sample, of 301 caregivers assigned to 28 medical and surgical services was randomly drawn after being paired according to age, gender and work schedule. Its size, calculated by Epi Info software (version 06), was equal to 301 caregivers spread in 28 services (156 women and 145 men).

The survey was based on a half-hour, face to face interview, conducted with each participant and focused mainly on the explanation of study objectives', anonymity procedure guarantee, the collection of the enlightened consent and the passing of the inquiry form. This form was structured and involved 71 items related to socio-professional characteristics associated to four validated questionnaires in French version. These questionnaires included the Job Content Questionnaire of Karasek [7], the Short Form Health Survey (SF 12) [8], some items of the Nordic questionnaire of Musculo Skeletal Disorders (MSD) [9] and the Work Ability Index (WAI) [10]. According to the score of the latter seven-dimensional scale, work capacity was estimated to be low if the score was between 7 and 27, moderate if it was between 28 and 36, good if it was between 37 and 43 and excellent if the score was over 44 [10].

The Nordic questionnaire of musculoskeletal disorders was used because of its ease of use, high sensitivity (estimated between $82.3 \%$ and 100\%) and specificity (82\%) [11] [12]. Concerning Job Content Questionnaire, studies demonstrated satisfactory internal coherence, with Cronbach's alpha coefficients between 0.65 and 0.90 [13].

In our study, the asses of the perceived mental workload, was inspired by one-dimensional subjective scales. It consists in asking the operator to evaluate the mental workload associated to his/her current activity, using a Likert scale with four levels: 1 = very light, 2 = light, $3=$ moderate and $4=$ heavy [14] [15] [16]. Concerning the workload associated with activities in the previously occupied work station, the operator was invited to a relative subjective evaluation which took the current activity as the "referent situation" [15] [16].

The Chi 2 test was used to compare two or more variables with a significant level set at 5\%. Concerning multivariate analysis, multiple decreasing linear regressions with a statistical thresholding in simple cross fixed at $10 \%$ was utilized to introduce variables to the initial model.

\section{Results}

The response rate of nurses was about $97.34 \%$ (293 caregivers).

\subsection{Socio-Professional Characteristics and Health Condition (Table 1)}

Among the 293 respondents, there were 142 women. Average age was equal to $42.6 \pm 21$ years. Younger caregivers were more graduates with a highly significant difference $\left(\mathrm{p}<10^{-3}\right)$. All included subjects were exercising nursing cares, 
Table 1. Socio-professional characteristics and health condition of the study population.

\begin{tabular}{|c|c|}
\hline \multicolumn{2}{|l|}{ Caracteristics } \\
\hline Sex ratio & 1.06 \\
\hline Meanage \pm and (extremes) & $42.6 \pm 21$ years ( 19 to 60 years) \\
\hline \multicolumn{2}{|l|}{ Dependent children among 142 females: } \\
\hline 0 child & $28(19.72 \%)$ \\
\hline 1 to 3 children & $93(65.49 \%)$ \\
\hline$\geq 3$ children & $21(14.79 \%)$ \\
\hline \multicolumn{2}{|l|}{ Medical antecedent: $\mathrm{n}(\%)$} \\
\hline At least one confirmed disease & $93(31.74 \%)$ \\
\hline Upper limb MSD symptoms & $150(51.20 \%)$ \\
\hline MSDs in the back & $204(69.62 \%)$ \\
\hline Average BMI & $26.5 \pm 3.49[17.4-8.3] \mathrm{kg} / \mathrm{m}^{2}$ \\
\hline overweight & $122(41.64 \%)$ \\
\hline Obesity & $61(20.82 \%)$ \\
\hline \multicolumn{2}{|l|}{ Grades: $\mathbf{n}(\%)$} \\
\hline Senior techniciens & $138(47.10 \%)$ \\
\hline Nurses & $111(37.88 \%)$ \\
\hline Nurse assistant. & $44(15.02 \%)$ \\
\hline \multicolumn{2}{|l|}{ Shiftofwork: n (\%) } \\
\hline Nightshift & $209(71.33 \%)$ \\
\hline Average period & $5.63 \pm 7.54$ years \\
\hline \multicolumn{2}{|l|}{ Health self-assessment: $n$ (\%) } \\
\hline Excellent or good & $167(57 \%)$ \\
\hline Average & $31(10.58 \%)$ \\
\hline Bad & $95(32.42 \%)$ \\
\hline Workability: WAI & $40 \pm 6.28[21-49]$ \\
\hline Excellent or good n (\%) & $177(60.41 \%)$ \\
\hline Bad & $116(39.59 \%)$ \\
\hline Desired age of retirement $<60$ years. & $22.52 \%$ \\
\hline Mean age of retirement & $54.13 \pm 4.10$ years \\
\hline \multicolumn{2}{|l|}{ Raisons of an early retirement: } \\
\hline - the content and conditions of work & $34.5 \%$ \\
\hline - in related to their health & $25.9 \%$ \\
\hline - other causes & $39.6 \%$ \\
\hline
\end{tabular}

but only $37.9 \%$ of them (111 caregivers) were nurses. The average job tenure was $18.51 \pm 12.87$ years [ $1-40$ years] with a significant prevalence of nurses among the caregivers and a greater seniority $(\mathrm{p}=0.004)$. Along their respective careers, $71.33 \%$ of caregivers (209) endured at least once the fixed night work, with an average of $5.63 \pm 7.54$ years without significant differences based on age or gender or grade.

Among caregivers, 31.68\% (93 caregivers) had at least one disease confirmed by a medical opinion. During the 12 months preceding the survey, $51.20 \%$ of them (150) had symptoms suggestive of upper limb musculoskeletal disorders and $69.62 \%$ (204 caregivers) suffered from low back pain. Addictive behavior to tobacco was noted among $17.74 \%$ of subjects (52) and concerned exclusively male caregivers.

Concerning the self-assessment of the work ability, the average WAI in the 
study population was equal to $40 \pm 6.28$ with a decrease of this capacity with age $(\mathrm{p}=0.005)$. Furthermore, the mean physical quality of life score was $42.64 \pm 3.22$ [17.96 - 63.62]. The physical Quality Of Life (QOL) was poor among 47.09\% of surveyed caregivers (138). Moreover, among questioned subjects, desired age of retirement was lower than the regulatory age (60 years) among $22.52 \%$ of careers (66). This early retirement was significantly expressed among workers aged less than 45 years $\left(\mathrm{p}<10^{-3}\right)$, female gender $(54.18 \%$ women versus $45.82 \%$ men $)(\mathrm{p}=$ $0.04)$ and those having a poor physical quality of life $(\mathrm{p}=0.024)$.

\subsection{Perceived Mental Workload and Psychosocial Factors}

Mental workload was perceived as "moderate" by 145 caregivers $(48.49 \%)$ and as "heavy" by 119 caregivers (40.61\% of them). The average number of years that caregivers had a work perceived as having an equivalent mental load to current work was 14.10 years \pm 11.88 . This previous mental workload was perceived heavier by 92 caregivers (31.39\%) during $3.07 \pm 7.11$ years. According to univariate statistical analysis, No significant difference in terms of perceived mental workload was found in function of age, gender or department. But, deteriorated physical QOL was associated with a heavier perceived mental workload ( $\mathrm{p}=$ 0.031).

According to the Karasek questionnaire, 58 caregivers (19.79\%) were on Job strain with no statistical correlation between Job strain and age, gender, grade or the department (Table 2). Unsatisfactory latitude was reported by 120 healthy workers $(41 \%)$. More than half of the caregivers felt that their activity was varied $(76.8 \%)$ that their work enabled them to develop professional skills $(57.34 \%)$. The majority of caregiver ( $86 \%$ of them) complained about the imposed operating procedures. A feeling of job insecurity was reported by $73.72 \%$ of the study population (216). This feeling was significantly more reported among workers affected to night shift $(\mathrm{p}=0.021)$.

Concerning the quality of life, the mean mental score according to SF-12 questionnaire was equal to $42.57 \pm 11.62$ [14.83 - 71.64]. A poor quality of mental life was noted among $49.8 \%$ surveyed caregivers (146). Furthermore, during the last four weeks preceding the survey, 73 caregivers $(24.91 \%)$ felt sad and down. During this same period, 123 caregivers (41.98\%) were unable to complete professional tasks as much as they would like to. According to univariate analysis, the quality of mental life was lower among caregivers with MSDs of spine or upper limbs ( $\mathrm{p}$ equal respectively to 0.002 and $<10^{-3}$ ), and those wishing an early retirement $(\mathrm{p}=0.001)$. Moreover, a significant decline in mental quality of life according to the WAI was retained $\left(\mathrm{p}<10^{-3}\right)$. In addition, this dimension of quality of life was altered among caregivers who lived a heavier mental load required by their job without a significant relationship $(p=0.06)$.

\subsection{Determinants of Mental Workload}

Multi-varied analytic study concluded that heavier perceived mental workload was correlated to varied determinants particularly age over then 45 years 
Table 2. Psycho-social characteristics of the study population (Karasek questionnaire).

\begin{tabular}{lc}
\hline \multicolumn{1}{c}{ Characteristics } \\
\hline Latitude & 2.8 \\
Median & $123(41 \%)$ \\
Unsatisfactory & \\
Psychological demand & $2.4[3.2-1.6]$ \\
Median & $214(71 \%)$ \\
Excessive & \\
Work relations & $181(60.1 \%)$ \\
Absence of support among colleagues & $166(55.3 \%)$ \\
Absence of support among superiors & $58(19.79 \%)$ \\
Job strain & $160(53.45 \%)$ \\
- Men & $171(56.89 \%)$ \\
- Aged $\geq 45$ years & $87(28.9 \%)$ \\
Active & $62(20.59 \%)$ \\
Passive & $86(28.57 \%)$ \\
Relaxed & $23(7.6 \%)$ \\
Iso-strain & \\
\hline
\end{tabular}

$\left(\mathrm{p}<10^{-3}\right)$, overweight or obesity $(\mathrm{p}=0.02)$, having more than three depending children $\left(\mathrm{p}<10^{-3}\right)$ lower degree obtained $\left(\mathrm{p}<10^{-3}\right)$, working grade as nurse assistant $(\mathrm{p}=0.001)$ and expressed willingness to an early retirement $(\mathrm{p}=0.031)$. Contrariwise, neither the low latitude nor the high psychological demand has been correlated to a heavier perception of the mental load (Table 3).

This final model is characterized by a low collinearity among the explanatory variables (VIF very Indices < to 10), but on the whole, the model explains only $30 \%$ of these variations ( $\mathrm{R}$ square).

\section{Discussion}

"Workload is a multidimensional and complex construct, that is affected by external task demands, environmental, organizational and psychological factors, and perceptive and cognitive abilities" [17] [18]. This construct is "used to describe the extent to which an operator has engaged the cognitive and physical resources required for a task performance" [3] [6] [18].

Recently many scientific researches focused on the mental workload, particularly in the health sector. But, although mental workload among nurses has received considerable attention in the literature issues, the measurement of this load among these workers have received considerably less attention [3] [18] [19]. In fact, the search based on the keyword "mental workload" and conducted on PubMed data base concluded to 2227 articles in which mental workload was mentioned. The combination of key words "mental workload" AND "nurses" produced 312 articles. But the key words combination of "nurses" AND "mental workload measurement" produced only 58 articles.

In this study we evaluate the perceived mental work load among a representative sample of all paramedics exercising nursing activities in two university hospitals in the center of Tunisia. 
Table 3. Analysis of multivariate determinants of perceived mental workload.

\begin{tabular}{|c|c|c|c|c|}
\hline \multirow{2}{*}{ Model } & \multicolumn{2}{|c|}{$\begin{array}{l}\text { Non-standardized } \\
\text { coefficients }\end{array}$} & \multirow{2}{*}{$\begin{array}{c}\begin{array}{c}\text { Standardized } \\
\text { coefficients }\end{array} \\
\text { Bêta }\end{array}$} & \multirow{2}{*}{ Significance } \\
\hline & A & $\begin{array}{c}\text { Standard } \\
\text { Error }\end{array}$ & & \\
\hline Age & 0.025 & 0.005 & -0.382 & 0.000 \\
\hline BMI & -0.006 & 0.013 & -0.029 & 0.002 \\
\hline Nomber of children & -0.53 & 0.034 & -0.106 & 0.000 \\
\hline Grade & 0.105 & 0.068 & 0.950 & 0.023 \\
\hline MSD's of Upper limb & -0.005 & 0.031 & -0.011 & 0.060 \\
\hline SF 12 physical score & 0.006 & 0.006 & 0.072 & 0.001 \\
\hline Desire of an early retirement & 0.280 & 0.131 & 0.148 & 0.031 \\
\hline
\end{tabular}

Several authors agree that, the notion of experienced and perceived mental workload seems to offer a subjective and empirical evaluation of the mental workload [1] [5] [15] [20] [21]. The evaluation of mental workload can be conducted based on methods which fall into one of the three following categories: performance-based measures, physiological measures and subjective measures, [3] [15] [16] [20]. Subjective measures consist usually on requiring subjects to quantify their experience of workload with different techniques. In practice, one or multidimensional scales are used with absolute or relative evaluation, collected immediately or retrospectively [16]. According to literature, the NASA Task Load Index (TLX) is the most reliable and valid instrument to assess the overall subjective workload. Reliability and Validity of NASA-TLX is well established to evaluate workload experienced among care workers especially nurses [18].

Our approach-inspired from unidimensional subjective scales-combined immediate absolute assessment and a retrospective-relative one. Firstly, operators were invited to evaluate the mental workload associated to their current activity on a four levels Likert scale. Then, they were asked to evaluate the workload associated to activities of previously occupied work station compared to this "referent situation". The use of relative retrospective judgment of subjective workload was strongly supported by different researches [15] [16]. It consist on the use of one task as a "reference task" with an arbitrarily assigned workload value and the evaluation of all other tasks' subjective workload value relatively to this reference task [15] [16]. It seems clear that one of major limits of our study it the non-use of validated scale. In fact, common techniques are complicated and time-consuming [3] [15] [16]. Moreover, we opted for an estimation of the global perception of mental workload associated to the global care activity and not to each task accomplished by the caregiver.

This study aimed also to identify individual and professional determinants of this perceived mental workload among the study population. Thus, we used during 
a face to face interview, four validated questionnaires to explore work-related stress (Job Content Questionnaire of Karasek) [7], the quality of life (the Short Form Health Survey-SF 12) [8], the work ability (WAI) [9], and some items of the Nordic questionnaire to explore musculoskeletal disorders [10]. The global homogeneity of the study' population and its good French proficiency (second official language in Tunisia), allowed the use of the validated version in French of these questionnaires.

In our series, the mental workload was perceived as "heavy" by $48.49 \%$ of caregivers, "moderated" by $40.61 \%$ and "light" by $10.9 \%$ of caregivers. Moreover, as reported in the literature, in our work this workload has been associated both with individual determinants and characteristics of the activity [1] [2].

\subsection{Individual Determinants}

Mental workload was perceived as heavier by caregivers aged 45 years or older. Several authors agree that the perceived mental workload is variable according to age [2] [22]. A study conducted by the Direction of Research Studies Evaluation and Statistics (DREES), among 5000 employees of healthcare establishments in France, concluded that older caregivers have a heavier perception of the mental workload [2]. In addition, the Longitudinal Study of Aging, Health and Work (VISAT) conducted among 3200 employees, followed over 10 years, retained that with the advancement of age, the workload is felt to be more painful [23]. Similarly, the study conducted by the Directorate for Research and Improvement of Conditions of Work (DIRACT) among 44.531 Belgian workers between 1999 and 2007 concluded that as workers grow up, they have a more difficult mental and cognitive experience [22]. According to this study, the advance in age is accompanied with an intensification of the problems of adaptation especially during a change of professional activity. Moreover, as workers grow up, they feel that they have less opportunity to be promoted and to develop skills through new learning [22].

In our study, the sex-ratio was equal to 1.06 , without significant correlation between perceived mental workload and gender. However, statistically significant correlation was found between this workload and the number of dependent children $\left(\mathrm{p}=10^{-3}\right)$. In the literature, the correlation between mental workload and gender has often been reported [22]. The perceived mental workload may also be influenced by extra-professional mental load. In fact, women often seem to be caught between the mental workload and the social responsibilities attributed to them at home [2] [22]. This is particularly noticeable among married women having depending children, who are constrained to supplementary extra-professional burdens [22]. Beyond a heavier perception of the mental workload, it should be noted that family concerns are often associated with greater absenteeism among women reducing their availability and their participation in continuing training. This explains in part the inequity between the gender in the experienced mental workload and the upgrading and the progression on the professional scale over years [24]. In addition, the study conducted by DIRACT 
between 1999 and 2007 among 44.531 Belgian workers notes a significant relationship between gender and the mental workload. Authors explained this finding partly by the fact that men work more freely and participate in dialogues and decision-making about their activity. In addition, men appear to have better relationships with colleagues both at professional and extra-professional activities [22].

In our study, $67.6 \%$ of caregivers felt their health status as moderate or even bad with a mean score of physical quality of life equal to $42.6 \pm 3.2$; and among them $39.59 \%$ rated their capacity of work as low. Among the subjects interviewed, one-third (31.68\%) had at least one confirmed pathology-type of obesity in $20.8 \%$ of cases-and more than the half (51.20\%) suffered from MSDs of upper limbs during the 12 months preceding the study.

The statistical analysis concluded that MSDs and an increased BMI have been correlated with heavier perceived mental workload ( $\mathrm{p}=0.060$ and 0.002$)$, as well as the willingness expressed by some caregivers to an early retirement ( $\mathrm{p}=$ 0.031). However a better physical quality of life score was associated with a significantly lighter perceived workload $(\mathrm{p}=0.001)$.

Many studies show a dual correlation between perceived workload and health status [2] [25]. Pathological conditions, including MSDs and obesity, are perceived as an obstacle and as an additional constraint to the activity. These conditions are added to the real difficulties of a proper exercise of care among this affected caregiver [26]. Caregivers feel that their resources are reduced and insufficient to deal with requires of the task. In contrast, workers with a good quality of physical life will have better evaluation of the balance of task requirementspersonal abilities [2]. Moreover, an over workload (physical or mental) can generate work-related pathologies and even premature wear of the organism [27]. Thus, this hyper-solicitation can reveal individual predispositions to pathologies, and can amplify the effects of aging and motivate workers to leave work early [28] [29].

\subsection{Professional Determinants}

The workload has been perceived heavier for the nurse assistant grade than nurses $(p=0.001)$. Moreover we did not found any statistical correlation between the perceived mental workload and the job tenure. Although, in several articles this variable is an independent determinant of perceived workload [2] [22] [28]. Indeed, the job tenure is associated with a professional experience that evolves over the years. Caregivers develop skills that allow them to face unforeseen and stressful situations at work. Different items reduce the mental and emotional costs of these situations. Among these elements, we note the acquisition of individual and collective adjustment strategies and the development of capacities of coping and control [2] [23] [30]. In our study, this correlation was not noted, probably due to the specificity of the care sector, and the lack of a continuous training that promotes the updating and development of apprenticeship among caregivers. 
Caregivers included in our study were senior technicians in $47.1 \%$ of cases, nurses in $37.9 \%$ and medical auxiliaries in $15 \%$ of cases, spread in 28 different hospital departments. Among them, 37.88\% had a primary level of education. Further training and higher grade have proven to be protective factors with less painful experienced workload. In most cases, despite a close correlation between the initial diploma and the degree reached, some caregivers, especially older ones, have progressed on the career ladder. Other authors have reported the correlation between the mental workload and training on one hand and between this workload and grade on the other hand [22] [31] [32]. The statistical correlation between the level of education and the perceived mental workload may be explained by the level of uncertainty faced by the caregiver, specifically in complex or ambiguous situations [2]. In fact, the prescribed organization of work has never been infallible especially in hospital sector. Grey zones and unpredictable situations hardly listed, persist in any real situation of work [2]. These unexpected events and incidents require special skills to manage mishaps [2]. In the care sector, this unforeseen event can be life-threatening for patients [2]. Whereas, less skilled people use their resources and capacities to manage these situations [2] [18]. Lack of knowledge or fear of not having sufficient knowledge in communication with the patient or those around him may also be a source of additional mental workload [2] [33].

Concerning the grade, it would seem that more graduated caregivers have less uncertainty about their future because they feel more satisfied their current grade, which would not enable them to progress at the career ladder [22] [30]. In addition, they have more confidence in the financial perspectives and employment opportunities offered to them thanks to their professional status [2] [22]. Moreover, some studies concluded that when the grade occupied by the paramedics is adapted to the performed task, the caregiver feels that his work is productive and useful which is a source well-being, satisfaction and can alleviate the perceived mental workload [2]. Furthermore, the monetary gratification of care assistants, while working as nurses, is considered as unsatisfactory and insufficient compared with the efforts made. This insufficient gratification can affect the perceived mental workload [28] [34].

Concerning work schedules, in our series, $15 \%$ of the caregivers surveyed worked on fixed night, $37.9 \%$ on a fixed day schedule and $47.1 \%$ on alternate hours. The average night job tenure was $7.88 \pm 7.54$ years. We concluded that atypical schedule of work were not retained as a determinant of a heavier perception of the mental workload. Contrary to our results, several studies agree that alternate schedules are associated with a high mental workload [2] [22] [23]. Indeed, the frequent changes in the schedule have an impact on the memorization and the processing of the data of the service, which is imperative in the nursing activity. In fact, the staff must know perfectly patients, their pathologies, their treatments and the different explorations requested. It has been shown that the difficulties of memorizing and processing data increase the mental workload [2]. It should be noted that, with this alternating schedule variability, there are 
also organizational changes that can occur. For example, the absence of a colleague generates a heavier absence to manage in restricted night shifts. These changes require a re-planning of tasks and impose adaptability to temporal contingencies, both on professional and extra-professional life, especially in families having dependent children [2].

\section{Conclusions}

According to our results, mental work load is perceived as "moderate to heavy" by nearly $90 \%$ of caregivers assuring nursing care in different departments of the two university hospital in the center of Tunisia implicated in the study. Moreover, this mental workload seems to be influenced by both individual and professional characteristics. Professional characteristics include degree obtained and working grade of workers affected to these cares activities. Additionally, heavier perceived mental workload is significantly associated to an expressed willingness to retire early.

These major results suggest the necessity of preventive actions to improve work conditions in hospitals, so that to alleviate perceived mental workload. Furthermore, future longitudinal studies focusing on the evaluation of preventive actions carried out in this work environment and its effects on perception and quality of life of nurses, safety of care and early retirement of work life should be conducted.

Finally, our study examined the perceived mental workload among caregivers affected to nursing care in a university hospital with non-use of validated scale. This latter represents the major limit of this study. Future studies based on validated instruments like NASA-TLX should be conducted among nurses to assess of the subjective mental workload. This evaluation should also examine other healthcare providers in different settings (first line hospitals, outpatient and day hospitalization, private clinics, etc.).

\section{References}

[1] Cuvelier, L. (2012) Quantitative Measurement of Mental Workload: Progress Limitations and Practice for the Prevention of Occupational Risks. Arch Env Med, 73, $120-126$.

[2] Rabassa, A. (2006) An Approach to the Concept of Workload by Studying the Professional Trajectories of the Healthcare staff of the Public Assistance of the Hospitals of Marseille. Ph.D. Dissertation, Faculty of Medicine of Marseille, France. (In French)

[3] Cain, B. (2007) A Review of the Mental Workload Literature. Report Contract No.: RTO-TR-HFM-121-Part-II, Defence Research and Development Canada Toronto Human System Integration Section, Toronto.

[4] Ozkan, A., Ozdeveciogl, M., Kaya, Y. and Özsahin Koc, F. (2014) Effects of Mental Workloads on Depression-Anger Symptoms and Interpersonal Sensitivities of Accounting Professionals. Revista de Contabilidad, 15, 2.

[5] Kataoka, J., Sasaki, M. and Kanda, K. (2011) Effects of Mental Workload on Nurses' Visual Behaviors during Infusion Pump Operation. Japan Journal of Nursing Science, 8, 47-56. https://doi.org/10.1111/j.1742-7924.2010.00158.x 
[6] Carayon, P. and Gurses, A.P. (Ronda G. Hughes, Ed.) (2008) Patient Safety and Quality: An Evidence-Based Handbook for Nurses. Chapter 30, Agency for Healthcare Research and Quality (US), Rockville.

[7] Niedhammer, I. (2002) Psychometric Properties of the French Version of the Karasek Job Content Questionnaire: A Study of the Scales of Decision Latitude, Psychological Demands, Social Support, and Physical Demands in the GAZEL Cohort. International Archives of Occupational and Environmental Health, 75, 129-144. https://doi.org/10.1007/s004200100270

[8] Younsi, M. and Chakroun, M. (2014) Measuring Health-Related Quality of Life: Psychometric Evaluation of the Tunisian Version of the SF-12 Health Survey. Quality of Life Research, 23, 2047-2054. https://doi.org/10.1007/s11136-014-0641-8

[9] Kuorinka, I., Jonsson, B., Kilbom, A., Vinsterbergh, H., Biering-Sorensen, F., Anderson, G. and Jorgensen, K. (1987) Standardised Nordic Questionnaires for the Analysis of Musculoskeletal Symptoms. Applied Ergonomics, 18, 233-237. https://doi.org/10.1016/0003-6870(87)90010-X

[10] Radkiewich, P. and Widerszal-Bazyl, M. (2005) Psychometric Properties of Work Ability Index in the Light of Comparative Survey Study. In: International Congress Series 1280, Elsevier, Amsterdam, 304-309.

[11] Descatha, A., Roquelaure, Y., Chastang, J.F., Evanoff, B., Melchior, M., Mariot, C., et al. (2007) Validity of Nordic-Style Questionnaires in the Surveillance of Upper-Limb Work-Related Musculoskeletal Disorders. Scandinavian Journal of Work, Environment \& Health, 33, 58-65. https://doi.org/10.5271/sjweh.1065

[12] Dickinson, C.E., Campion, K. and Foster, A.F. (1992) Questionnaire Development an Examination of the Nordic Musculoskeletal Questionnaire. Applied Ergonomics, 23, 197-201.

[13] Lesagea, X., Berjotb, S., Amourab, C., Deschampsa, F. and Grebotc, E. (2012) French Questionnaires Assessing Stress at Work: A Review. Archives des Maladies Professionnelles et de P Environnement, 73, 596-606.

[14] Meyer, J.P. (2014) Subjective Assessment of the Workload, the Borg Scale. References on Occupational Medicine N 139. (In French)

[15] Rubio, S., Díaz, E., Martín, J. and Puente, J.M. (2004) Evaluation of Subjective Mental Workload: A Comparison of SWAT, NASA-TLX, and Workload Profile Methods. Applied Psychology: An International Review, 53, 61-86. https://doi.org/10.1111/j.1464-0597.2004.00161.x

[16] Tsang, P.S. and Vidulich, M.A. (2006) Mental Workload and Situation Awareness. In: Salvendy, G., Ed., Handbook of Human Factors and Ergonomics, 243-268. https://doi.org/10.1002/0470048204.ch9

[17] Weinger, M.B., Reddy, S.B. and Slagle, J.M. (2004) Multiple Measures of Anesthesia Workload during Teaching and Nonteaching Cases. Anesthesia \& Analgesia, 98, 1419-1425. https://doi.org/10.1213/01.ANE.0000106838.66901.D2

[18] Hoonakker, P., Carayon, P., Gurses, A., Brown, R., McGuire, K., Khunlertkit, A. and Walker, M.J. (2011) Measuring Workload of ICU Nurses with a Questionnaire Survey: The NASA Task Load Index (tlx). IIE Transactions on Healthcare Systems Engineering, 1, 131-143. https://doi.org/10.1080/19488300.2011.609524

[19] MacNeela, P., Scott, A., Treacy, P. and Hyde, A. (2007) Reconsidering the Conceptualization of Nursing Workload: Literature Review. Journal of Advanced Nursing, 57, 463-471. https://doi.org/10.1111/j.1365-2648.2006.04134.x

[20] Meshkati, N., Hancock, P. and Rahimi, M. (1992) Techniques in Mental Workload Assessment. In: Wilson, J. and Corlett, E., Eds., Evaluation of Human Work. A Practical Ergonomics Methodology, 605-627. 
[21] Brun, J.P., Biron, C., Martel, J. and Ivers, H. (2002) Evaluation of Mental Health at Work: An Analysis of Human Resource Management Practices. Chair in Occupational Health and Safety Management.

[22] Vets, C., Notelaers, G. and De Witte, H. (2009) Analysis of the Psychological Workload in Belgium: Summary of 10 Years of Research Based on the Diract Database. Federal Public Service Mission Employment and Social Dialogue. (In French)

[23] Marquié, J.C., Tucker, P., Folkard, S. and Gentil, C.A. (2015) Chronic Effects of Shift Work on Cognition: Findings from the VISAT Longitudinal Study. Occupational and Environmental Medicine, 72, 258-264. https://doi.org/10.1136/oemed-2013-101993

[24] Bahu, M., Coutrot, T., Herbet, J.B., Mermilliod, C. and Rouxel, C. (2010) Professional Career and Health Status, Drees/Dares, Solidarity and Health, 14 January. (In French)

[25] Guez, M. and Abadia, G. (2012) Prevention of the Arduousness of Work: Meeting of the Four Occupational Health Societies of Ile-de-France Paris (2011). References on Occupational Health, 130, 108-115.

[26] Van den Berg, T., Elders, L., de Zwart, B. and Burdorf, A. (2009) The Effects of Work-Related and Individual Factors on the Work Ability Index: A Systematic. Occupational and Environmental Medicine, 66, 211-220. https://doi.org/10.1136/oem.2008.039883

[27] Vendramin, P. and Valenduc, G. (2012) Occupations and Ageing at Work. Working Paper, WP 2012.09.

[28] Nicot, A.M. and Roux, C. (2008) Workability: An Approach through Wear Processes and Professional Itineraries. Editions Network Anact.

[29] Marquié, J.C. and Jolivet, A. (2006) Work, Cognitive Development Factor or Premature Wear? Retirement \& Society, 49, 180-187.

[30] Tjeka, R. (2005) The Occupational Physician towards the Aging Worker: What Data from the Medical Examination Could Help to Assess the Capacity of Work in Trades with High Physical Demands. Memory, Leuven.

[31] David, H., Volkoff, S., Cloutier, E. and Derriennic, F. (2001) Aging, Work Organization and Health. Electronic Review PISTES, 3, 1-32. (In French)

[32] Huret, A.F. (2013) Study of Age-Related Cognitive Differences as a Function of the Level of Creative Ability of Individuals. Memoir in Psychology, Nice.

[33] Lourel, M. (2006) The Relations to Work, Control and Health in Call Center-Consumer Service. Psychologie du Travail et des Organisations, 12, 39-51.

[34] Bier, B. and Belleville, S. (2010) Optimizing Cognition in Aging: Brain Reserve, Cognitive Stimulation and Cerebral Plasticity. Revista Neuropsicologia Latinoamericana, 2, 37-47. (In French) 